\title{
Seroresponse to the second measles vaccine dose at school entry in Qassim province, Saudi Arabia
}

\author{
M.K.M. Khalil, 'H.M. Nadrah, ${ }^{2}$ O.A. Al Yahia ${ }^{3}$ and G. ElGhazali ${ }^{4}$
}

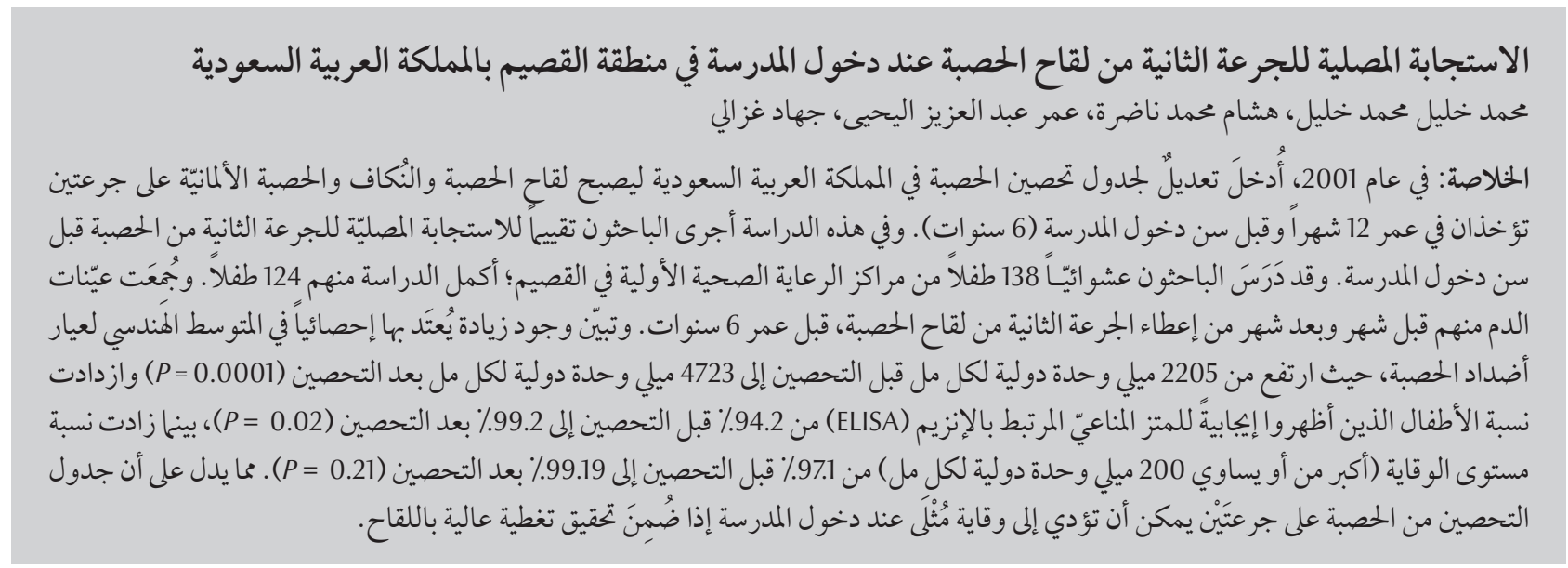

ABSTRACT In 2001, the measles immunization schedule in Saudi Arabia was changed to 2 measles, mumps and rubella vaccine doses at 12 months and at 6 years. In this follow-up study we evaluated the seroresponse to the second measles dose before school entry. We recruited 138 children randomly from primary health care centres in Qassim; 124 children completed the study. Blood samples were collected before and 1 month after giving the second measles dose, before the age of 6 years. There was a statistically significant increase in the geometric mean titre of measles antibody, from $2205 \mathrm{~m} \mathrm{IU} / \mathrm{mL}$ before vaccination to $4723 \mathrm{mIU} / \mathrm{mL}$ after $(P=0.0001)$. The proportion of children with positive ELISA results increased fro++ $94.2 \%$ before vaccination to $99.2 \%$ after $(P$ $=0.02)$, while the proportion with protective level $(\geq 200 \mathrm{mIU} / \mathrm{mL})$ increased from $97.1 \%$ before vaccination to $99.19 \%$ after $(P=0.21)$. The 2-dose measles immunization schedule can produce optimum protection at school entry if high vaccination coverage is guaranteed.

\section{Réponse sérologique à la seconde dose du vaccin antirougeoleux à l'entrée à l'école primaire dans la Province de Qassim (Arabie saoudite)}

RÉSUMÉ En 2001, le programme de vaccination antirougeoleuse en Arabie saoudite est passé à deux doses du vaccin antirougeoleux-antiourlien-antirubéoleux, la première à 12 mois et la seconde à 6 ans. Dans la présente étude de suivi, nous avons évalué la réponse sérologique à la seconde dose du vaccin antirougeoleux avant l'entrée à l'école primaire. Nous avons recruté 138 enfants de façon aléatoire dans des centres de soins de santé primaires de la province de Qassim. Au total, 124 enfants ont terminé l'étude. Des échantillons de sang ont été recueillis avant, puis un mois après l'administration de la seconde dose du vaccin antirougeoleux, avant l'âge de 6 ans. Le titre moyen géométrique des anticorps antirougeoleux a présenté une augmentation statistiquement significative, passant de $2205 \mathrm{mUI} / \mathrm{ml}$ avant la vaccination à $4723 \mathrm{mlU} / \mathrm{ml}$ après $(P=0,0001)$. La proportion d'enfants ayant des résultats de test ELISA positifs est passée de 94,2\% avant la vaccination à 99,2 \% après $(P=$ $0,02)$. La proportion d'enfants ayant un taux d'anticorps protecteur ( $\geq 200 \mathrm{mUI} / \mathrm{ml}$ ) est passée de $97,1 \%$ avant la vaccination à $99,19 \%$ après $(P=0,21)$. Le programme de vaccination antirougeoleuse en deux doses peut induire une protection optimale à l'entrée à l'école primaire lorsqu'une forte couverture vaccinale est assurée.

'Department of Communicable Diseases (Vaccinology) \& Research Development, Medical Research Administration, Ministry of Health, Riyadh, Saudi Arabia (Correspondence to M.K.M. Khalil:statkhl@hotmail.com).

${ }^{2}$ Riyadh Region Health Affairs, Ministry of Health, Riyadh, Saudi Arabia.

${ }^{3}$ Family Medicine Department, Training and Research Centre, Ministry of Health, Qassim, Saudi Arabia

${ }^{4}$ Virology Department, Laboratory of King Fahd Medical City, Riyadh, Saudi Arabia.

Received: 24/05/09; accepted: 27/08/09 


\section{Introduction}

Globally, measles remains a leading cause of death in children despite the availability of a safe vaccine for the past 40 years [1].

The measles vaccine was introduced in Saudi Arabia as single-dose schedule of Schwartz measles vaccine for children aged 1-9 years in 1974. In 1982 measles vaccination at 9 months became a requirement for obtaining the birth certificate, a step which aimed to increase the coverage rate. In 1991, a change in the measles immunization schedule was introduced: a standard dose of the Edmonston-Zagreb (E-Z) vaccine at 6 months of age was included in a 2-dose policy as part of the measles elimination strategy, where measles, mumps and rubella (MMR) vaccine was given additionally at the age of 12 months. The main aim of this new measles immunization policy was to solve the problem of primary measles vaccine failure due to persistent maternal antibody [2] and to protect children under 9 months $[3,4]$. The impact of implementing the 2-dose schedule and maintaining a high coverage of $>90 \%$ has been reflected in the epidemiological pattern of measles in Saudi Arabia; measles cases decreased in the age groups $1-4$ and $5-15$ years $[5,6]$.

As expected in the control phase, a pool of susceptible children started to accumulate at the level of school-age groups. It included older children without vaccination, or with only 1 measles vaccination, and younger children with vaccine failure even after the 2-dose schedule. This pool of susceptible children was detected by the improved surveillance [7].

A strategy of the measles elimination phase is to maintain the number of susceptible individuals in the population below the critical number required to sustain transmission of the measles virus; therefore an MMR campaign targeting school-age children was conducted during 1998-2000. Pre-and post-campaign blood samples were collected to evaluate the immune response to the MMR given in the campaign. Prevaccination positivity rate measured by enzyme-linked immunosorbent assay (ELISA) and geometric mean titre of first grade children was significantly lower than in children in the 6th grade [8]. This finding was supported by the surveillance system, which showed that the proportion of measles cases was greater in the age group 1-5 years [7]. After the campaign, the protection rate reached almost $100 \%$.

The use of a 2-dose MMR schedule, with the 1st dose at 12 months and the 2nd at pre-school age, was implemented in $2001[9,10]$. Although this was based on the previous epidemiological and serological studies, no seroresponse study was done to evaluate the new schedule. Furthermore, after implementing this new schedule, outbreaks started to occur in certain parts of Saudi Arabia [11].

The response to the first MMR dose (the new schedule, given at 12 months) has been evaluated previously. Seropositivity increased from $3.5 \%$ before vaccination to $100 \%$ after [12]. The aim of this study was to evaluate the seroresponse to the second measles dose given at school entry in Qassim province. The results of this study, along with the results of the previous study [12], can be used to evaluate the seroresponse to the new vaccination schedule.

\section{Methods}

\section{Overall design}

This was a follow-up study in which blood samples were collected from children at school entry before and 4 weeks after giving the second MMR dose. Using ELISA, paired measles IgG levels were assayed. Mean measles antibody titre, proportion of children with positive measles antibody level before and after the second dose and seroconversion were calculated on the paired sera.

The study was conducted through primary health care (PHC) centres in the Qassim area during the vaccination visits before school entry at 6 years of age. Inclusion criteria were: Saudi Arabian nationality, age 5-6 years, vaccinated with MMR at 12 months of age, guardian gave consent for child's participation, no history of measles or fever with rash, and available for the study period. Children with history of chronic illness, immunocompromised disorder or corticosteroid use were excluded.

A sample size of 180 children was planned, allowing for a 30\% drop-out at the second visit to end with 120 children. The sample was calculated with $95 \%$ confidence and $80 \%$ power, assuming a $90 \%$ proportion with protective level before vaccination and a null hypothesis of $80 \%$. Taking into consideration the drop-out, 110 children would be enough to calculate the proportion with protective levels.

We used a multistage sampling technique: in the first phase, $10 \mathrm{PHC}$ centres were selected using computergenerated randomization from the total of 142 PHC centres listed. In the second stage, 18 children were invited to participate randomly from the MMR vaccination list at each PHC centre.

\section{Serology}

From each participant, 3-5 mL of blood were collected by venepuncture. The blood sample was centrifuged and sera were divided into 2 cryotubes, $1 \mathrm{~mL}$ each. These were stored at $-20^{\circ} \mathrm{C}$ until shipment to the reference laboratory. Laboratory work was done in the King Fahd Medical City Laboratory, Riyadh.

A commercial enzyme (Enzygnost ${ }^{\circledR}$ Anti-Measles-Virus/IgG, Dade Behring, Germany) was used to detect virus-specific $\operatorname{IgG}$ against measles virus according to the manufacturer's instructions as described previously [12]. The 
quantitative antibody values for measles were expressed in International Units (IU). Equivocal results were repeated. If the results were confirmed, the samples were classed as equivocal, otherwise as positive or negative. The cut-off values for the Dade Behring assay were: positive: $>0.200$ optical density $(\mathrm{OD}) / 300 \mathrm{mIU} / \mathrm{mL}$; negative: $<0.100 \mathrm{OD} / 150 \mathrm{mIU} / \mathrm{mL}$ and equivocal: $0.100 \mathrm{OD}<\Delta \mathrm{A}$ sample $<0.200$ OD (values between 150-300 $\mathrm{mIU} / \mathrm{mL}$ )

Positive antibody was defined as "positive by ELISA"; seroconversion was defined as "negative to positive, or more than double the ELISA titre comparing pre- and post-vaccination titre"; protective level was defined as titre $\geq 200 \mathrm{mIU} / \mathrm{mL}$ [13-15].

SPSS, version 13, was used for data entry and analysis. Data are presented as mean antibody titre, geometric mean titre and proportion of children positive or seroconverted with $95 \%$ confidence intervals.

\section{Results}

Of the 140 children who attended the first visit, 66 were males (47.1\%) and 74 females (52.9\%). Out of 138 children who completed the first visit, 124 children completed the study with preand post-measles vaccination blood samples (Figure 1). Mean age was 64.97 (standard deviation 4; range 60-83) months.

The data were examined to test if they fit normal or skewed distribution. Measles antibody titre (IU/mL) showed a skewed distribution (skewness $=2.028$, kurtosis $=7.615)$, while OD was normally distributed.

There was a significant increase in post-vaccination measles antibody titre compared to pre-vaccination (paired $t$ test, $P=0.0001)$ (Table 1). A significant correlation was also found between pre- and post-vaccination titres $(r=$ 0.677 ).

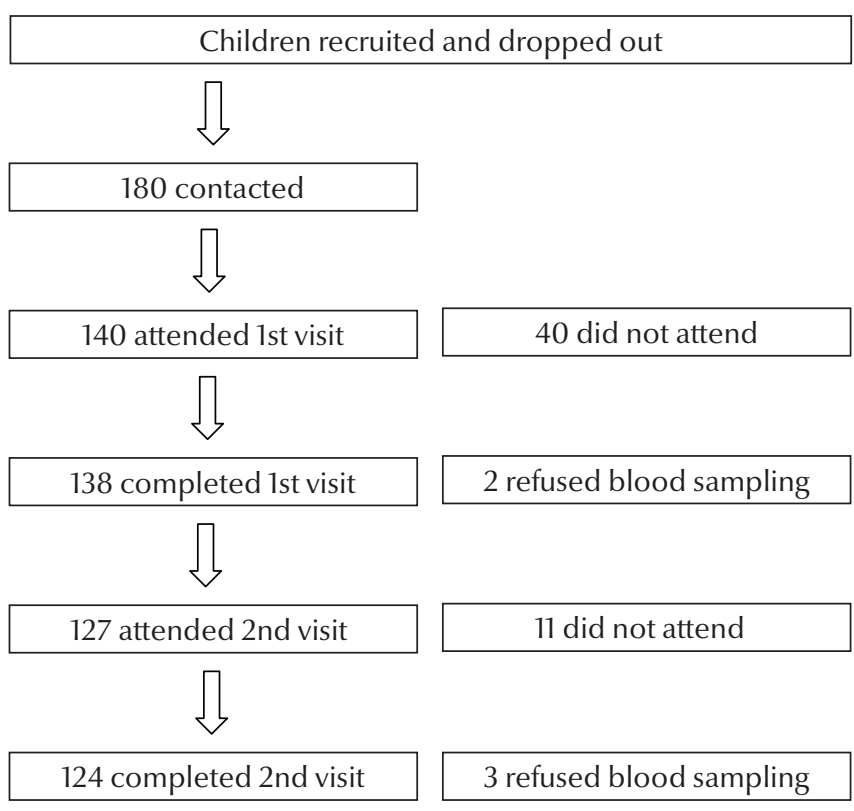

Figure 1 Flowchart showing children recruited and drop-outs

Only 3 out of 138 children who attended the first visit were negative before vaccination. After vaccination 99.2\% (123/124) became positive (Table 2). All the 14 children who attended only the first visit were positive for measles antibody. This means that the positivity rate actually increased from 93.55\%(116/124) to $99.2 \%(123 / 124)$ $(P=0.02)$. The antibody titre of 4 out of the 5 children with equivocal ELISA results were above $200 \mathrm{mIU} / \mathrm{mL}$ before vaccination.

Seroconversion was only $18 \%$ (25/124) using the double optic density as definition. Only $14 \%(20 / 124)$ showed a 4 -fold rise in titre.

\section{Discussion}

The use ofELISA positivityas a surrogate for protection is very conservative, as the cut-off value for positivity is around 300 $\mathrm{mIU} / \mathrm{mL}$, while the conventional protective level is $\geq 200 \mathrm{~m} \mathrm{IU} / \mathrm{mL}[14,15]$. Antibodies may be detected by plaque neutralization (PNT) in negative sera assayed by ELISA, as the PNT cut-off is $50 \mathrm{mIU} / \mathrm{mL}$ [16]. Comparing commercial ELISA with plaque reduction neutralization test showed $92 \%$ agreement, with a sensitivity of $90 \%$ and specificity of 100\%; ELISA performed adequately for immunity testing [17].

Before vaccination, $94.2 \%$ of the children in our study were positive for measles antibody, which agrees with the assumption used in our sample calculation that $90 \%$ would be positive/protected. This lies within the 95\% confidence interval of our results (88.52-97.28).

Comparing our results with other studies should take into consideration laboratory methods used, cut-off and definition of positivity and protection and, more importantly, criteria of inclusion. In our study, an important criterion of inclusion was confirmed administration of the first dose of measles at 12 months of age.

In an American study only 1\% were negative for measles antibody at 4-6 years old using the PNT test compared to $2.1 \%$ in our study using ELISA [18].

Aserosurvey in the western region in Saudi Arabia among vaccinated children showed measles seropositivity using ELISA in the age group 4-6 years was 


\begin{tabular}{|c|c|c|c|}
\hline \multirow[t]{2}{*}{ Laboratory assay } & \multicolumn{2}{|c|}{ Measles response } & \multirow[t]{2}{*}{$P$-value } \\
\hline & Before $(n=138)$ & After $(n=124)$ & \\
\hline \multicolumn{4}{|l|}{ ELISA } \\
\hline Optical density, mean (SD) & $0.916(0.482)$ & $1.278(0.469)$ & 0.0001 \\
\hline \multicolumn{4}{|l|}{ Antibody titre $m I U / m L$} \\
\hline Geometric mean & 2205 & 4723 & 0.0001 \\
\hline Median & 2510 & 5392 & \\
\hline Minimum & 2 & 2 & \\
\hline Maximum & 13342 & 29857 & \\
\hline
\end{tabular}

$M M R=$ measles, mumps and rubella; ELISA = enzyme-linked immunosorbent assay; $S D=$ standard deviation.

\begin{tabular}{|c|c|c|c|c|c|c|c|}
\hline \multirow[t]{2}{*}{ Laboratory parameter } & \multicolumn{3}{|c|}{$\begin{array}{l}\text { Before vaccination } \\
\qquad(n=138)\end{array}$} & \multicolumn{3}{|c|}{$\begin{array}{l}\text { After vaccination } \\
\qquad(n=124)\end{array}$} & \multirow[t]{2}{*}{$P$-value } \\
\hline & No. & $\%$ & $95 \% \mathrm{Cl}$ & No. & $\%$ & $95 \% \mathrm{Cl}$ & \\
\hline Negative & 3 & 2.2 & & 1 & 0.8 & & \\
\hline Equivocal & 5 & 3.6 & & - & & & \\
\hline Positive & 130 & 94.2 & 88.52-97.28 & 123 & 99.2 & 94.94-99.94 & 0.03 \\
\hline Protective level $(\geq 200 \mathrm{mIU} / \mathrm{mL})$ & 134 & 97.1 & 92.29-99.96 & 123 & 99.2 & 94.93-99.96 & 0.21 \\
\hline
\end{tabular}

$M M R=$ measles, mumps and rubella; $\mathrm{CI}=$ confidence interval .

$73.7 \%[10]$. This is very low compared to our findings. This was done in a different region and the difference may be a result of uncertainty about vaccination status or use of a different cut-off point in the laboratory for positive results. We should also take into consideration that our study is a follow-up seroresponse study.

According to our study, the proportion of children who were seronegative in Qassim met the World Health Organization target level: $<15 \%$ in those aged $2-4$ years, $<10 \%$ in those aged 5-9 years and $<5 \%$ in those aged $10-19,20-39$ and $40+$ years [19].

Almost all the children (99.2\%) became positive after receiving the second dose of the MMR vaccine. This is consistent with other studies adopting 1 year and pre-school MMR vaccination $[18,20]$. Other studies did not show such a high response to the second dose: in South Korea only 93.5\% were positive after the second dose. But samples were not collected shortly after the second dose in a follow-up study but as a seroprevalence study, and it is expected that positivity will decrease with time [21].

Longitudinal studies show that measles antibody levels reach a peak at 1-2 months post-vaccination then decrease 4-8-fold within 1 year and continue to decline with a half-life of about 2-4 years over $1-10$ years post-vaccination [22]. Also, measles vaccine-induced antibody titres will decrease with time post-vaccination when no wild measles virus circulates to boost antibody titres. In our study, less than $20 \%$ showed a seroconversion, reflecting a secondary immune response [21].

Measles can still occur in highly vaccinated populations and in communities with herd immunity of 90\% [23-25]. Elimination of measles requires continued commitment to increase vaccination coverage levels, the genetic analysis of circulating strains, and serosurveys of vaccinated individuals to establish the population at risk of contracting the infection [26].

\section{Acknowledgements}

This study was supported by King Abdel Aziz City for Science and Technology, grant number LGP-12-1. The investigators acknowledge with thanks the contribution of Maria Bas for performing the laboratory assay, and Mughram Alamry from the measles and polio unit in the central laboratory and his staff. The contribution of Mr Falah Al Mazrou, Director General of Preventive Health in the Ministry of Health and Dr Abdulla AlSaigul, Assistant Director General for primary care in Qassim, in facilitating the work, is highly appreciated.

This research could not have been done without the dedicated efforts in the field work of Dr Fahmy Hussein Imam, Dr Mohamed Hamdy, Dr Mohamed Zaky, Dr Taher Fatoh Hagag, Dr Kamal Fawazy Azam, Dr Magdi Ahmed Shahen, Dr Alaa Abdelatif, Dr Sahar Khalil and Dr Mohamed Almokhtar. Our appreciation also goes to all nurses and technicians in the PHC centres which participated in the study. 


\section{References}

1. Measles. Geneva, World Health Organization, 2009 (Fact sheet $\mathrm{N}^{\circ} 286$, http://www.who.int/mediaentre/factsheets/ fs286/en/index.html, accessed 15 December 2010).

2. Passive acquired immunity against measles in infants born to naturally infected and vaccinated mothers Medical Science Monitor, 2003, 9(12):CR541-546.

3. Abanamy A et al. Follow-up study for measles maternal antibodies and seroconversion after measles vaccination. Annals of Saudi Medicine, 1991, 11:51-53.

4. Carson MM et al. Follow up of infants given measles vaccine at 6 months of age. Vaccine, 2005, 23(25):3247-3255.

5. Khalil M. Follow-up study of children vaccinated against measles at the age of six months with $3.0 \log _{10}$ Edmonston-Zagreb. Saudi Medical Journal, 1993, 14(1):44-45.

6. Al-Mazrou YY et al. Measles immunization: early two-dose experience. Journal of Tropical Pediatrics, 1999, 45:98-104.

7. Khalil $\mathrm{M}$ et al. Response to measles revaccination among toddlers in Saudi Arabia by the use of two different trivalent measles-mumps-rubella vaccine. Transactions of the Royal Society of Tropical Medicine and Hygiene, 1999, 93:214-219.

8. Khalil $\mathrm{M}$ et al. Measles immunization in Saudi Arabia:the need for change. Eastern Mediterranean Health Journal, 2000, 7(4/5):829-834.

9. Al-Mazrou $\mathrm{Y}$ et al. Sero-response to measles-mumps-rubella vaccine campaign in Saudi Arabia. Saudi Medical Journal, 2002, 23(6):680-683.

10. Khalil M et al. Measles immunization in Saudi Arabia: from control to elimination. Annals of Saudi Medicine, 2005 25(4):324-328.

11. Jaber SM. A serological survey of measles, mumps and rubella immunity among school aged children in Western Saudi Arabia. Saudi Medical Journal, 2006, 27(1):63-69.

12. Khalil MK et al. Sero-response to measles vaccination at 12 months of age in Saudi infants in Qassim Province. Saudi Medical Journal, 2008, 29(7):1009-1013.

13. Tischer A, Gerik E. Immune response after primary and revaccination with different combined vaccines against measles, mumps, Rubella.Vaccine, 2000, 18(14):1382-1392.

14. Chen RT et al. Measles antibody evaluation of protective titres. Journal of Infectious Diseases, 1990, 162:1036-1042.
15. Albrecht P, Herrmann K, Burns GR. Role of virus strain in conventional and enhanced measles plaque neutralization test. Journal of Virological Methods, 1981, 3:251-260.

16. Sushil J et al. Serological response to early measles vaccination. Journal of Tropical Pediatrics, 2004, 50:175-177.

17. Szenborn L et al. Measles immunity testing:comparison of two measles IgG ELISAs with plaque reduction neutralization assay. Journal of Virological Methods, 2006, 131(2):209-212.

18. LeBaron $\mathrm{CW}$ et al. Persistence of measles antibodies after 2 doses of measles vaccine in a postelimination environment. Archives of Pediatrics \& Adolescent Medicine, 2007, 161(3):294301.

19. Andrews $\mathrm{N}$ et al. Towards elimination: measles susceptibility in Australia and 17 European countries, Bulletin of the World Health Organization, 2008, 86(3):161-240.

20. Vesikari T, Baer M, Willems P. Immunogenicity and safety of a second dose of measles-mumps-rubella-varicella vaccine in healthy children aged 5 to 6 years. Pediatrric Infectious Disease Journal, 2007, 26(2):153-158.

21. Kremer JR, Schneider F, Muller CP. Waning antibodies in measles and rubella vaccinees-a longitudinal study. Vaccine, 2006, 24(14):2594-2601.

22. Lee MS, Nokes DJ. Predicting and comparing long-term measles antibody profiles of different immunization policies. Bulletin of the World Health Organization, 2001, 79(7):615-624.

23. Lee MS et al. Post mass-immunization measles outbreak in Taoyuaun County, Taiwan; dynamic of transmission, vaccine effectiveness, and herd immunity. International Journal of Infectious Diseases, 1998, 3(2):64-69.

24. Progress toward measles mortality reduction and eliminationEastern Mediterranean Region, 1997-2007. Morbidity \& Mortality Weekly Report, 2008, 57(10):262-267.

25. Bernard $\mathrm{H}$ et al. An outbreak of measles in Lower Bavaria, Germany, January-June 2007. Eurosurveillance, 2007, 12(10):E071004.1.

26. Argüelles $M$ et al. Measles virus-specific antibody levels in individuals in argentina who received a one-dose vaccine. Journal of Clinical Microbiology, 2006, 44(8):2733-2738. 